\title{
Plasma characteristics of Ag:Al alloy produced by fundamental and second harmonic frequencies of Nd:YAG laser
}

\author{
Ali A-K. Hussain, Ahmed Abd Al-Razzaq \\ Department of Physics, College of Science, University of Baghdad, Baghdad, Iraq \\ E-mail: draliakh97@ scbaghdad.edu.iq
}

\begin{abstract}
In this work, the spectra for plasma glow produced by pulse $\mathrm{Nd}$ :YAG laser ( $\lambda=532$ and $1064 \mathrm{~nm}$ ) on Ag:Al alloy with same molar ratio samples in distilled water were analyzed by studying the atomic lines compared with aluminum and silver strong standard lines. The effect of laser energies of the range 300 to $800 \mathrm{~mJ}$ on spectral lines, produced by laser ablation, were investigated using optical spectroscopy. The electron temperature was found to be increased from 1.698 to $1.899 \mathrm{eV}$, while the electron density decreased from $2.247 \times 10^{15}$ to $5.08 \times 10^{14} \mathrm{~cm}^{-3}$ with increasing laser energy from 300 to $800 \mathrm{~mJ}$ with wavelength of $1064 \mathrm{~nm}$. The values of electron temperature using second harmonic frequency are greater than of $1064 \mathrm{~nm}$, which increased from 2.405 to $2.444 \mathrm{eV}$, while the electron density decreased from $2.210 \times 10^{15}$ to $1.516 \times 10^{15} \mathrm{~cm}^{-3}$ with increasing laser energy for the same energy range.
\end{abstract}

Key words

Pulse laser, spectroscopy, Boltzmann plot, plasma characteristics.

\section{Article info.}

Received: Sep. 2016

Accepted: Nov. 2016

Published: Dec. 2016

$$
\begin{aligned}
& \text { دراسة خصائص البلازما لسبيكة Ag:Al المتولدة بواسطة ليزر Nd:YAG وللترددات } \\
& \text { الأساسي و التوافقي } \\
& \text { علي عبد الكريم حسين، أحمد عبد الرزاق نعمة }
\end{aligned}
$$

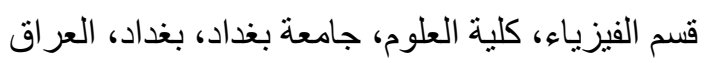

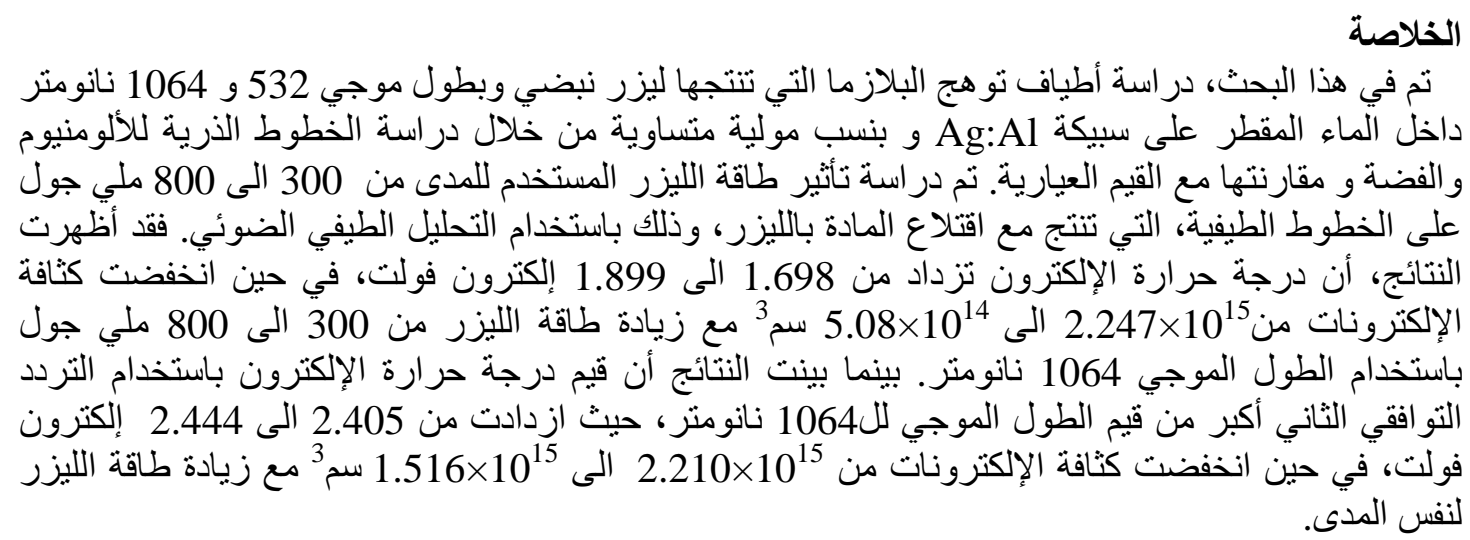

\section{Introduction}

Plasma diagnostics are used to obtain information about the nature of plasma, such as the chemical compositions and species of the plasma, density of the plasma, electron temperature [1]. Pulsed laser-induced plasmas of metals and alloys have more interest as they used in several applications such as synthesize of Nano-particles [2] investigation on elemental content [3] spectroscopic studies [4]. Light emitted in a wide range for spectroscopic analysis from the plasma generated by high- power laser pulses were detected and the 
resulting spectrum distribution. A spectrum often consists of a number of characteristic spectral lines of a particular atom or ion [5].

The electron temperature of plasma was calculated using Boltzmann relation [6]:

$\operatorname{Ln}\left(\frac{I_{m n} \lambda_{m n}}{g_{m} A_{m n}}\right)=\left(\frac{E_{m}}{K T_{e}}\right)+\left(\frac{N(T)}{U(T)}\right)$

where $\lambda_{m n}, I_{m n}, g_{m}$, and $A_{m n}$ are the wavelength, intensity, statistical weight, and transition probability between the transition states of upper level (m) and lower level (n), respectively.

The electron density was calculated using Saha-Boltzmann equation for atom and ion spectral lines emitted from the plasma [7]:

$n_{e}=$

$\frac{2\left(2 \pi m_{e} k T\right)^{3 / 2}}{h^{3}} \frac{I_{m n}^{I} A_{j k} g_{j}^{I I}}{I_{j k}^{I I} A_{m n} g_{m}^{I}} e^{-\left(E_{i o n}+E_{j}^{I I}-E_{m}^{I}\right) / k T}$

where $E_{\text {ion }}, E_{m}$ and $E_{j}$ are the ionization energy, the upper level energies of neutral and single ionized transitions, respectively.

The Coulomb interaction range in plasma is reduced due to the screening effect. The screening scale length, called the Debye length $\left(\lambda_{D}\right)$ was calculated as follows [8]:

$\lambda_{D}=\left(\frac{k_{\beta} T_{e}}{4 \pi e^{2} n_{0 e}}\right)^{1 / 2} \approx 743\left(\frac{T_{e}(e V)}{n_{0 e}\left(\mathrm{~cm}^{-3}\right.}\right)^{1 / 2}$

An important criterion for an ionized gas to be a plasma is that it should be dense enough so that $\mathrm{L}>>\lambda_{D}$.

While the plasma frequency can be calculated as follows [7]:

$\omega_{p}=\sqrt{\frac{N_{e} q_{e}^{2}}{\epsilon_{o} m_{e}}}$

plasma oscillations can only develop if the mean free time $\tau_{\mathrm{n}}$ between collisions is long enough compared to the oscillation period.
This condition is a criterion for an ionized gas to be considered a plasma.

The concept of Debye shielding developed if the number of particles in a Debye sphere, $\mathrm{N}_{\mathrm{D}}>>1$. [7]

$N_{D}=n_{e}\left[\frac{4 \pi \lambda_{D}^{3}}{3}\right]=\frac{1.38 \times 10^{6} T_{e}^{3 / 2}}{n_{e}^{1 / 2}}$

where $\mathrm{T}_{\mathrm{e}}$ in $\mathrm{K}$.

\section{Experimental part}

Ag:Al alloy were prepared using equal molar quantities of silver and aluminum powder and mix them by mechanical motor with steel balls at 10 minutes. A piston under a pressure of 3.5 tons was used to make a disk of 1 gm Ag:Al alloy with $0.9 \mathrm{~cm}$ diameter and $0.3 \mathrm{~cm}$ thickness. The sample was put in the bottom of $5 \mathrm{ml}$ quartz tube filled by distilled water. The samples were bombarded by $\mathrm{Nd}$ :YAG pulse laser $(9 \mathrm{~ns}$ duration and $10 \mathrm{~Hz}$ frequency) with two wavelengths (532 and $1064 \mathrm{~nm}$ ) and several energies (300, 400, 500, 600, 700 and $800 \mathrm{~mJ}$ ). The emitted spectrum from the surface of samples was studied by optical fiber to be analyzed using a spectrometer connected with a computer to study the effect of laser energy and wavelength on the properties of the produced plasma.

\section{Results and discussion}

We have produced plasma from the laser interaction with Ag:Al alloy target using Q-switched Nd:YAG in distilled water.

\section{Ag:Al target plasma in water using $1064 \mathrm{~nm}$ laser}

The optical emission spectra of Ag:Al plasma in distilled water were recorded by using optical emission spectroscopy technique with $1064 \mathrm{~nm}$ Nd-YAG laser. Fig. 1 shows the spectroscopic patterns for laser induced on Ag:Al surface with different laser energies from 300 to $800 \mathrm{~mJ}$, with $100 \mathrm{~mJ}$ step in distilled 
water. A comparison between observed peaks and standard Ag I, Ag II, Al I and Al II data [9] were done. This figure shows that the dominant peaks identify with Ag II standard lines. Most of the peaks appeared within the range of (160 to $280 \mathrm{~nm}$ ), except for some peaks belonging to Ag I located at (520.50 and $546.23 \mathrm{~nm}$ ) and for Al I (at $596.01 \mathrm{~nm}$ ). The emission spectrum intensity increased with increasing laser energy this results is agreement with Huang et al. [10].

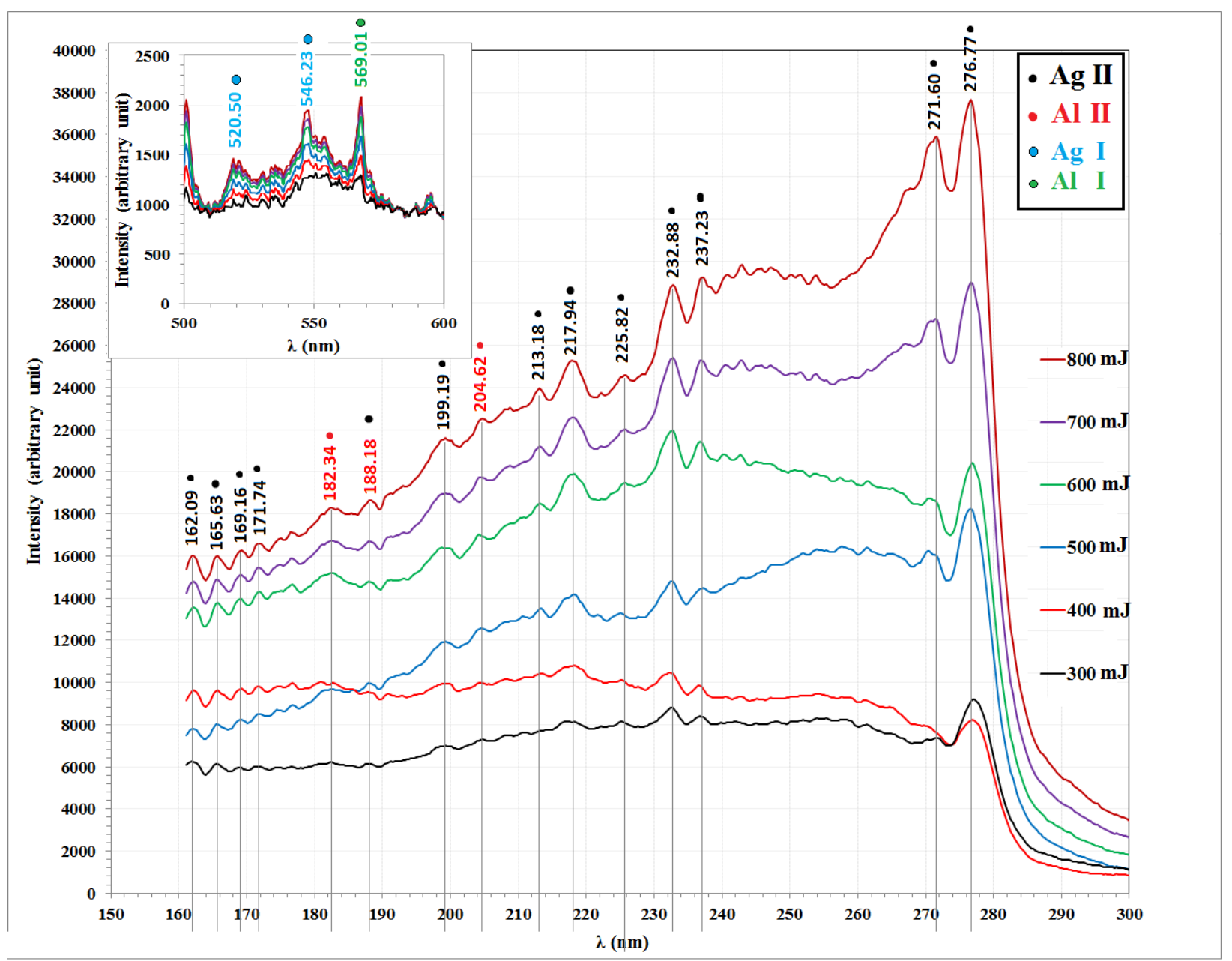

Fig. 1: Emission spectra induced by $1064 \mathrm{~nm}$ laser, with different laser energies for Ag:Al alloy in distilled water.

The value of $\mathrm{T}_{\mathrm{e}}$ is obtained from the Boltzmann plot method, as shown in Fig. 2, from the analysis of the nine recorded Ag II lines for plasma induced on Ag:Al alloy in distilled water using $1064 \mathrm{~nm}$ laser, at different laser energies 300, 400, 500, 600, 700 and $800 \mathrm{~mJ}$. The values of $\mathrm{T}_{\mathrm{e}}$ were estimated from the inverse of the slope of a linear best fit for the result values.

The fitting equations and the $\mathrm{R}^{2}$ were shown in the figure for all fitting lines. $\mathrm{R}^{2}$ is a statistical coefficient indicating the goodness of the linear fit which takes a value between $(0,1)$. The better one have $\mathrm{R}^{2}$ value closer to 1 [11]. 

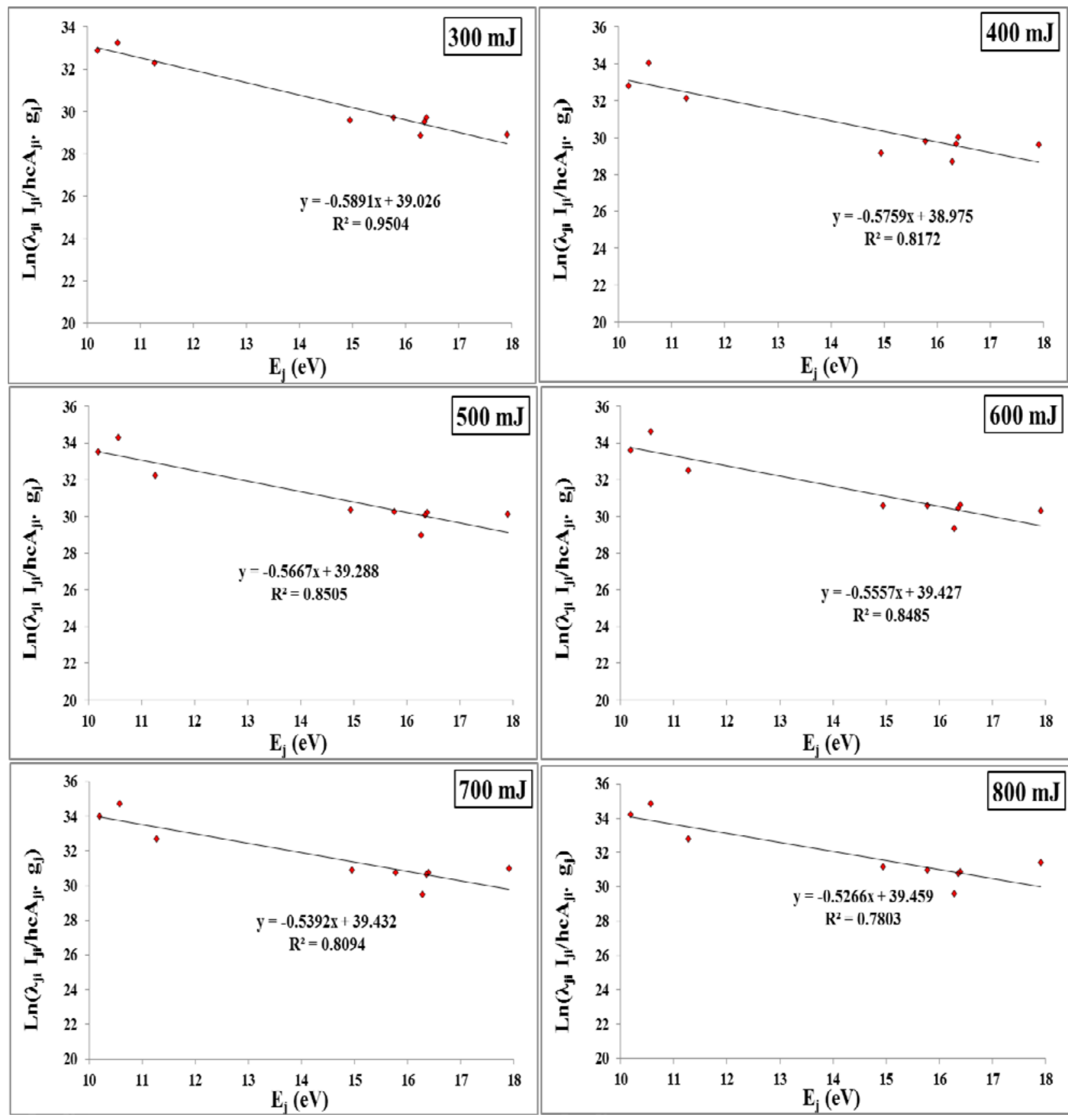

Fig. 2: Boltzmann plot method from the analysis of nine Ag II lines for Ag:Al alloy in distilled water using $1064 \mathrm{~nm}$ laser, with different laser energies. The best fit straight line, its equation and average relative standard deviation values $R^{2}$ are shown.

Electron temperature $\left(\mathrm{T}_{\mathrm{e}}\right)$ was calculated from the slope of fitting line using Eq. (5) and electron density $\left(\mathrm{n}_{\mathrm{e}}\right)$ using Saha-Boltzmann equation. Fig. 3 shows the variation of $\mathrm{T}_{e}$ and $\mathrm{n}_{\mathrm{e}}$ with laser energy. This figure shows that the $\mathrm{T}_{\mathrm{e}}$ increase with increasing laser energy, while $n_{e}$ decrease with increasing laser energy when varies from 300 to $800 \mathrm{~mJ}$. 


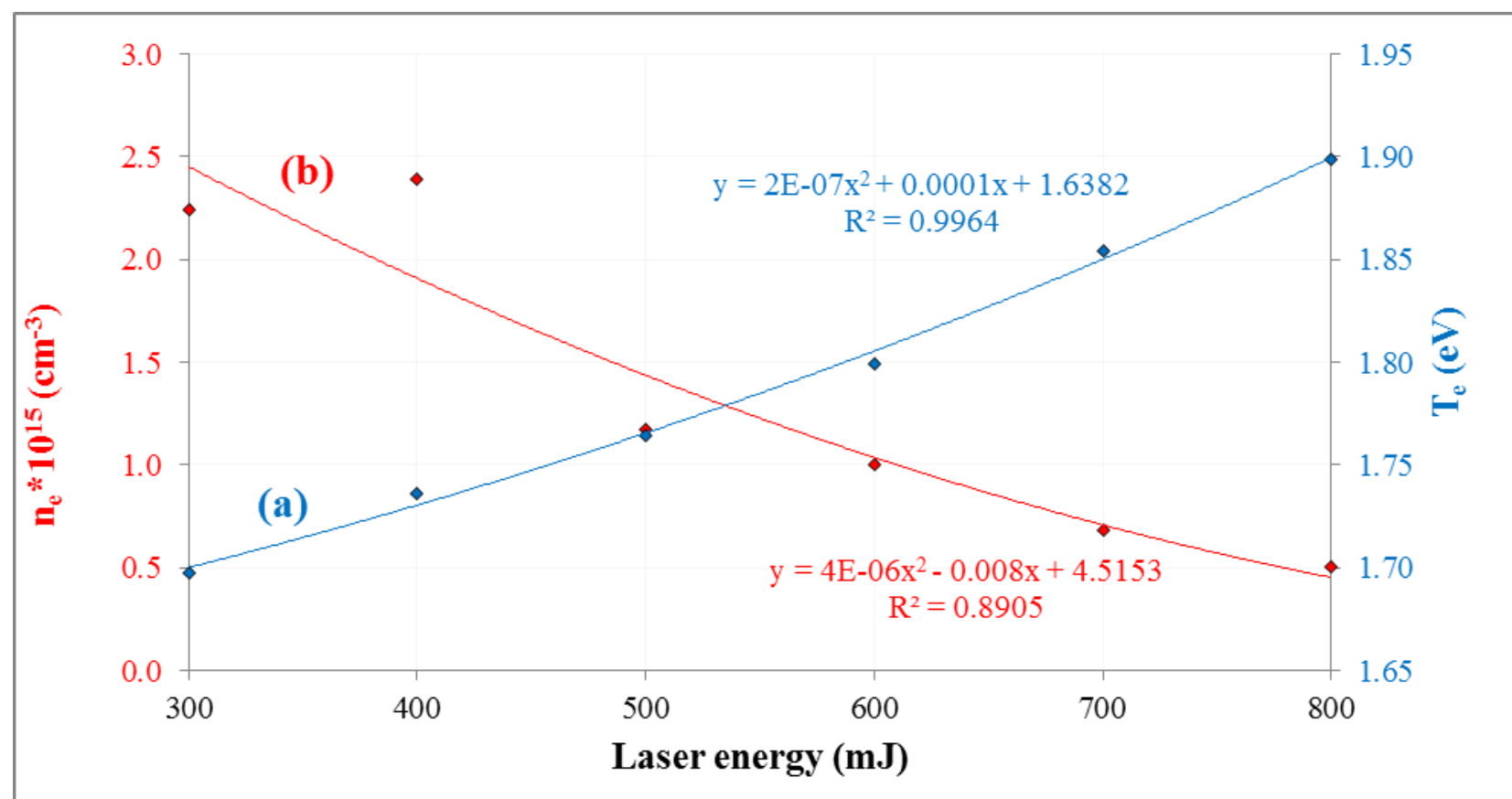

Fig. 3: The variation of (a) $T_{e}$ and (b) $n_{e}$ with laser energy for plasma indused on Ag:Al alloy in distilled water using $1064 \mathrm{~nm}$ laser.

Table 1 shows the calculated values of Debye length $\left(\lambda_{\mathrm{D}}\right)$, plasma frequency $\left(\mathrm{f}_{\mathrm{p}}\right)$ and Debye number $\left(\mathrm{N}_{\mathrm{d}}\right)$ at different laser energies. All calculated plasma parameters were satisfied the plasma conditions.

Table 1: Plasma parameters calculated from spectroscopy lines for Ag:Al alloy in distilled water using $1064 \mathrm{~nm}$ laser, with different laser energies.

\begin{tabular}{|c|c|c|c|}
\hline Laser energy $\mathbf{( m J )}$ & $\mathbf{f}_{\mathbf{p}}(\mathbf{H z}) * \mathbf{1 0}^{\mathbf{1 1}}$ & $\left.\boldsymbol{\lambda}_{\mathbf{D}} \mathbf{( c m}\right)$ & $\mathbf{N}_{\mathbf{d}} * \mathbf{1 0}^{\mathbf{4}}$ \\
\hline $\mathbf{3 0 0}$ & 4.257 & 0.00020 & 8.017 \\
\hline $\mathbf{4 0 0}$ & 4.391 & 0.00020 & 7.943 \\
\hline $\mathbf{5 0 0}$ & 3.075 & 0.00029 & 11.620 \\
\hline $\mathbf{6 0 0}$ & 2.840 & 0.00031 & 12.957 \\
\hline $\mathbf{7 0 0}$ & 2.343 & 0.00039 & 16.429 \\
\hline $\mathbf{8 0 0}$ & 2.025 & 0.00045 & 19.697 \\
\hline
\end{tabular}

\section{Ag:Al target plasma in distilled} water using $532 \mathrm{~nm}$ Nd:YAG laser

Fig. 4 shows the spectroscopy patterns for laser induced on Ag:Al surface with different laser energies 300, 400, 500, 600, 700 and $800 \mathrm{~mJ}$. Most of the peaks appeared within the range of (160 to $280 \mathrm{~nm}$ ), except for some peaks belonging to Ag I (at $338.62 \mathrm{~nm}$ ). This result is agreement with Musadiq et al. [12]. The emission spectrum intensity increase with increasing laser energy. The dominant peaks identify belong Ag II standard lines. 


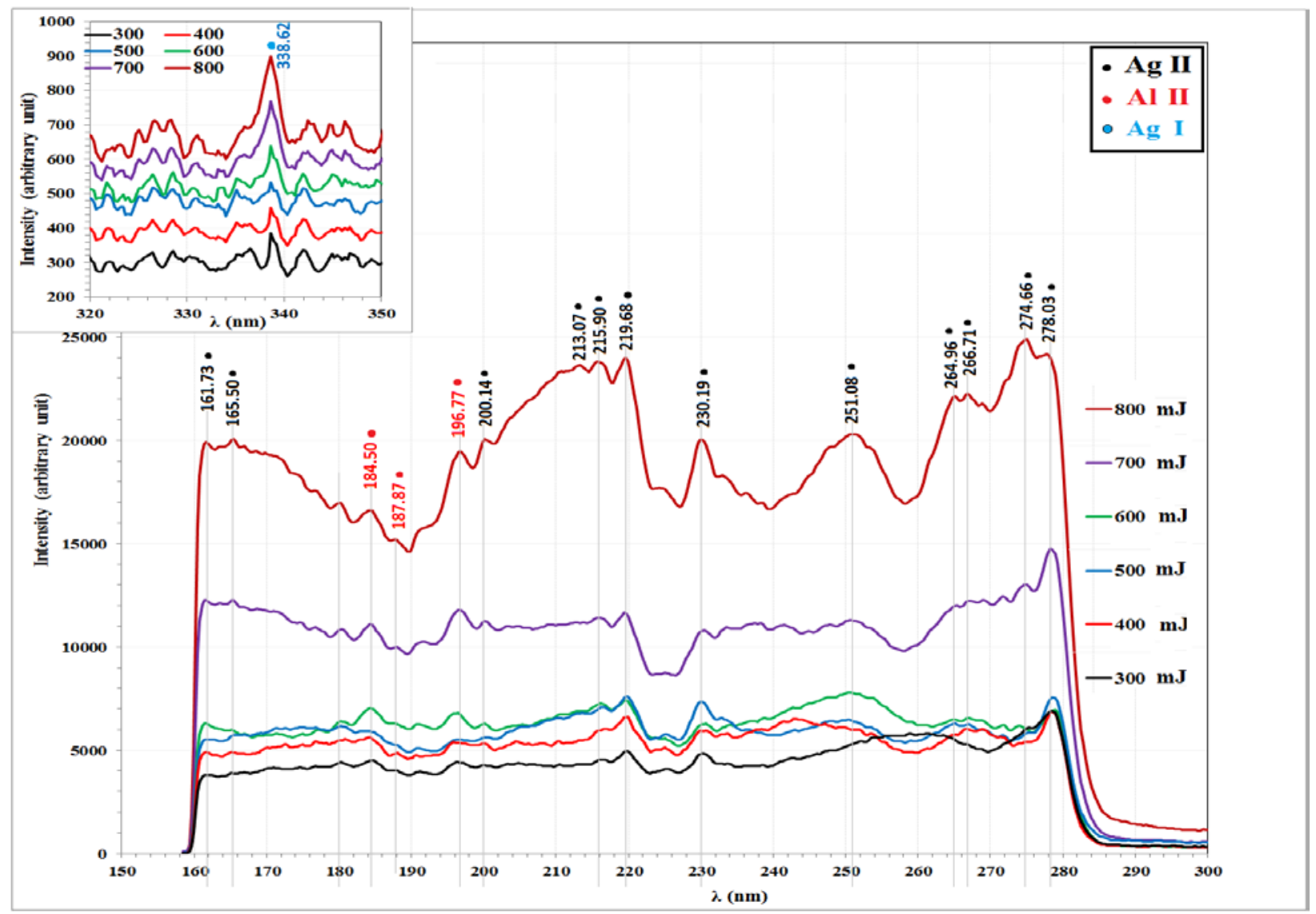

Fig. 4: Emission spectra induced by $532 \mathrm{~nm}$ laser, with different laser energies for Ag:Al alloy in distilled water.

The values of $\mathrm{T}_{\mathrm{e}}$ were obtained from the Boltzmann plot, as shown in Fig. 5, from the analysis of the nine recorded Ag II peaks for plasma induced on Ag:Al alloy in distilled water using $532 \mathrm{~nm}$ laser, with different laser energies 300, 400, 500, 600,700 and $800 \mathrm{~mJ}$. The values of $\mathrm{T}_{\mathrm{e}}$ were estimated from the inverse of the slope of a linear best fit for the result values. The fitting equations and $\mathrm{R}^{2}$ were shown in the figure for all fitting lines.
The same behavior for plasma temperature $\left(T_{e}\right), T_{e}$ increase with laser energy, and electron density $\left(\mathrm{n}_{\mathrm{e}}\right)$ in $532 \mathrm{~nm}$ as in $1064 \mathrm{~nm}$ and at different laser peak powers in distilled water as shown in Fig. 6, but with higher values in $532 \mathrm{~nm}$ because the high kinetic energy gained to ejected electrons from higher photons energies [13]. $n_{e}$ increase reaching maximum values at $600 \mathrm{~mJ}$ laser energy, then decrease with more laser energy. 


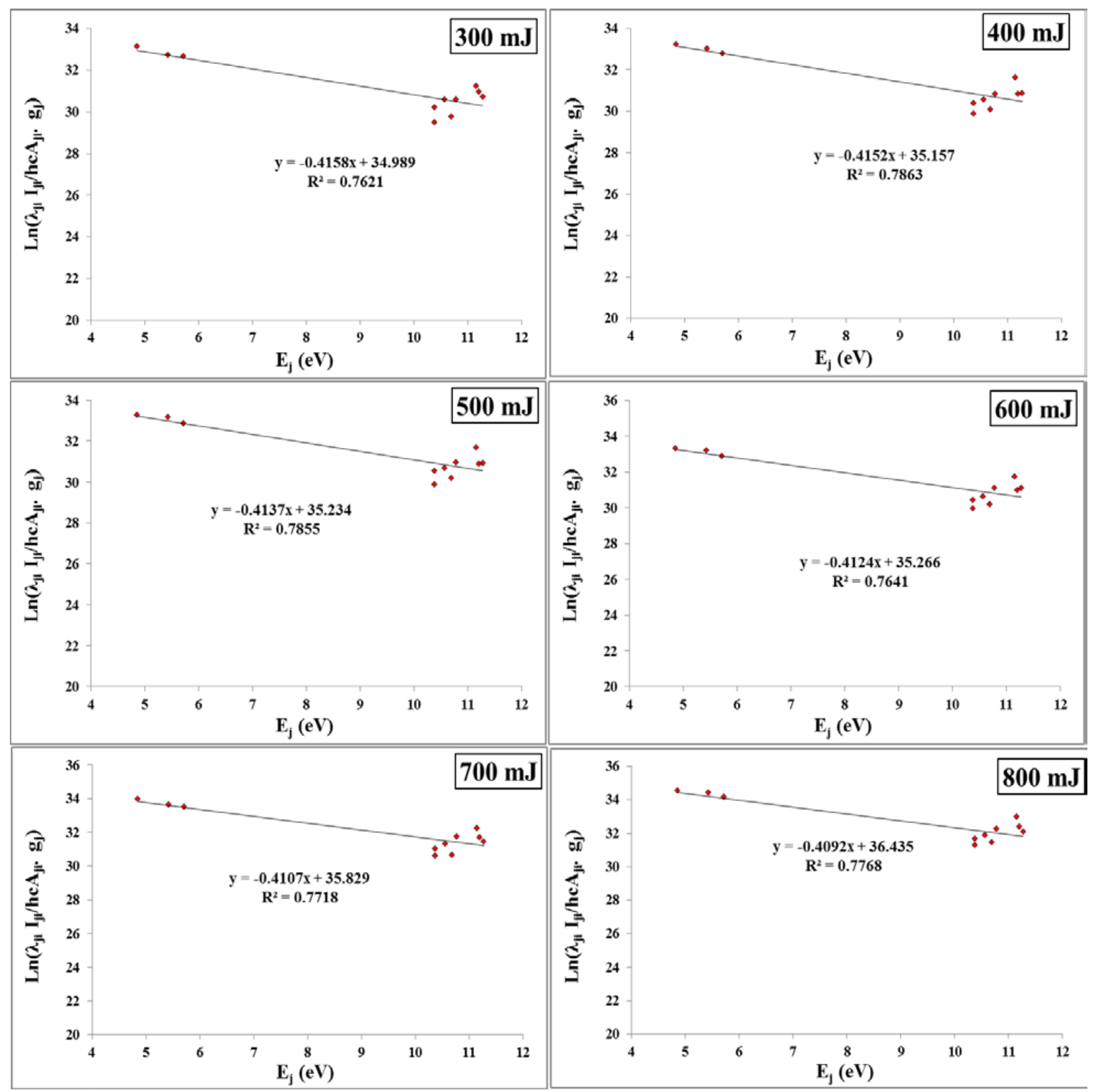

Fig. 5: Boltzmann plot made from the analysis of nine Ag II lines for Ag:Al alloy in distilled water using $532 \mathrm{~nm}$ laser, with different laser energies. The best fit straight line, its equation and average relative standard deviation values $R^{2}$ are shown. 


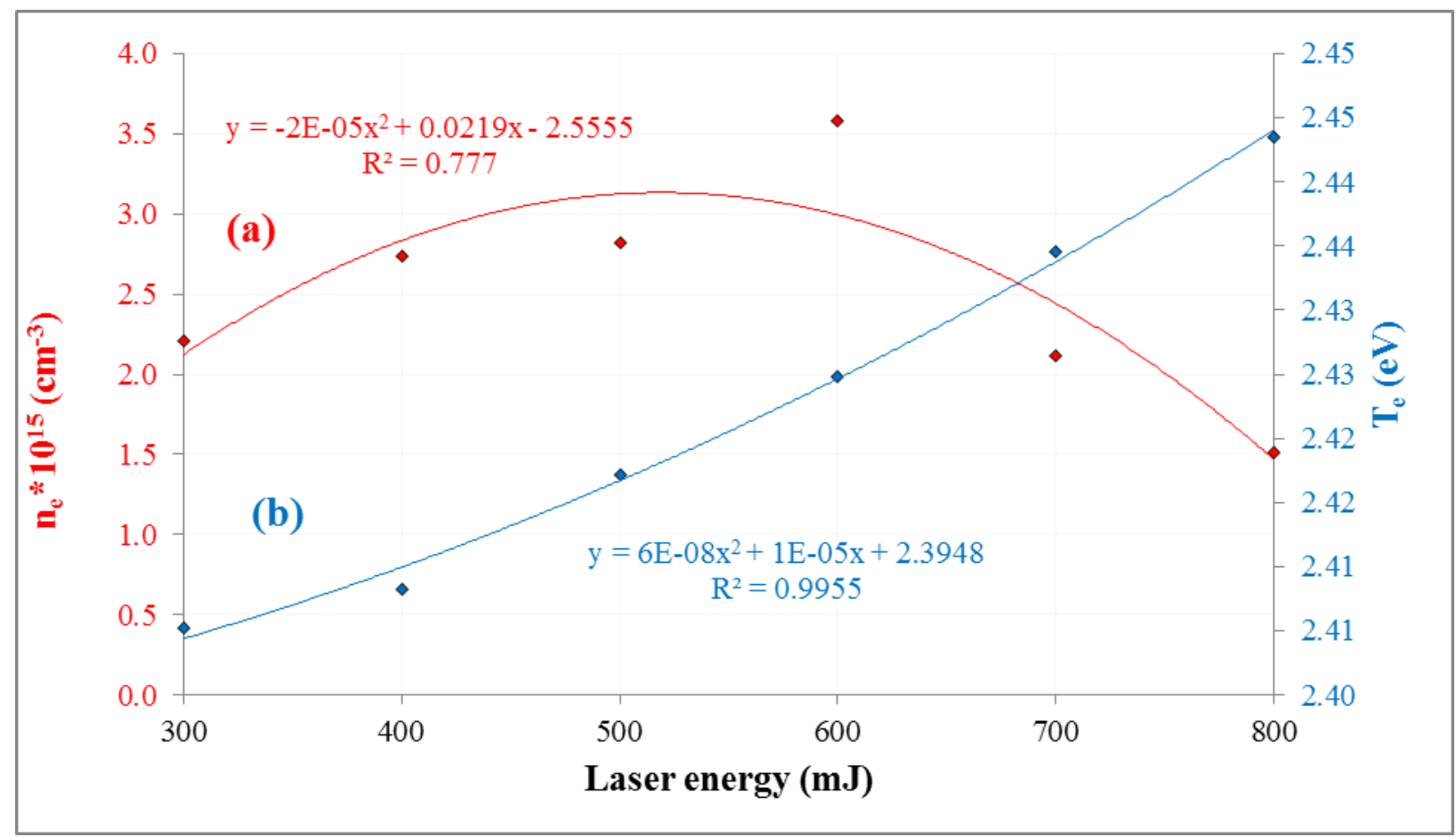

Fig. 6: The variation of (a) $T_{e}$ and (b) $n_{e}$ with laser energy for plasma indused on Ag:Al alloy in distilled water using $532 \mathrm{~nm}$ laser.

Table 2 shows Debye length $\left(\lambda_{D}\right)$, number $\left(N_{d}\right)$ at different laser energies. plasma frequency $\left(f_{p}\right)$ and Debye

Table 2: Plasma parameters calculated from spectroscopy lines for Ag:Al alloy in distilled water using $532 \mathrm{~nm}$ laser, with different laser energies.

\begin{tabular}{|c|c|c|c|}
\hline Laser energy $\mathbf{( m J})$ & $\mathbf{f}_{\mathbf{p}}(\mathbf{H z}) * \mathbf{1 0}^{\mathbf{1 1}}$ & $\left.\boldsymbol{\lambda}_{\mathbf{D}} \mathbf{( c m}\right)$ & $\mathbf{N}_{\mathbf{d}} * \mathbf{1 0}^{\mathbf{4}}$ \\
\hline $\mathbf{3 0 0}$ & 4.222 & 0.00025 & 13.633 \\
\hline $\mathbf{4 0 0}$ & 4.699 & 0.00022 & 12.122 \\
\hline $\mathbf{5 0 0}$ & 4.767 & 0.00022 & 12.015 \\
\hline $\mathbf{6 0 0}$ & 5.374 & 0.00019 & 10.710 \\
\hline $\mathbf{7 0 0}$ & 4.132 & 0.00025 & 14.014 \\
\hline $\mathbf{8 0 0}$ & 3.497 & 0.00030 & 16.650 \\
\hline
\end{tabular}

Fig.7 shows the spectroscopy patterns, at the range 550 to $900 \mathrm{~nm}$, for laser induced on Ag:Al surface using $532 \mathrm{~nm}$ laser. A set of peaks appeared and with similar position for all samples within the range of 580 to 890, previous studies have shown that one of the emission band for distilled water molecule within this range [14]. 


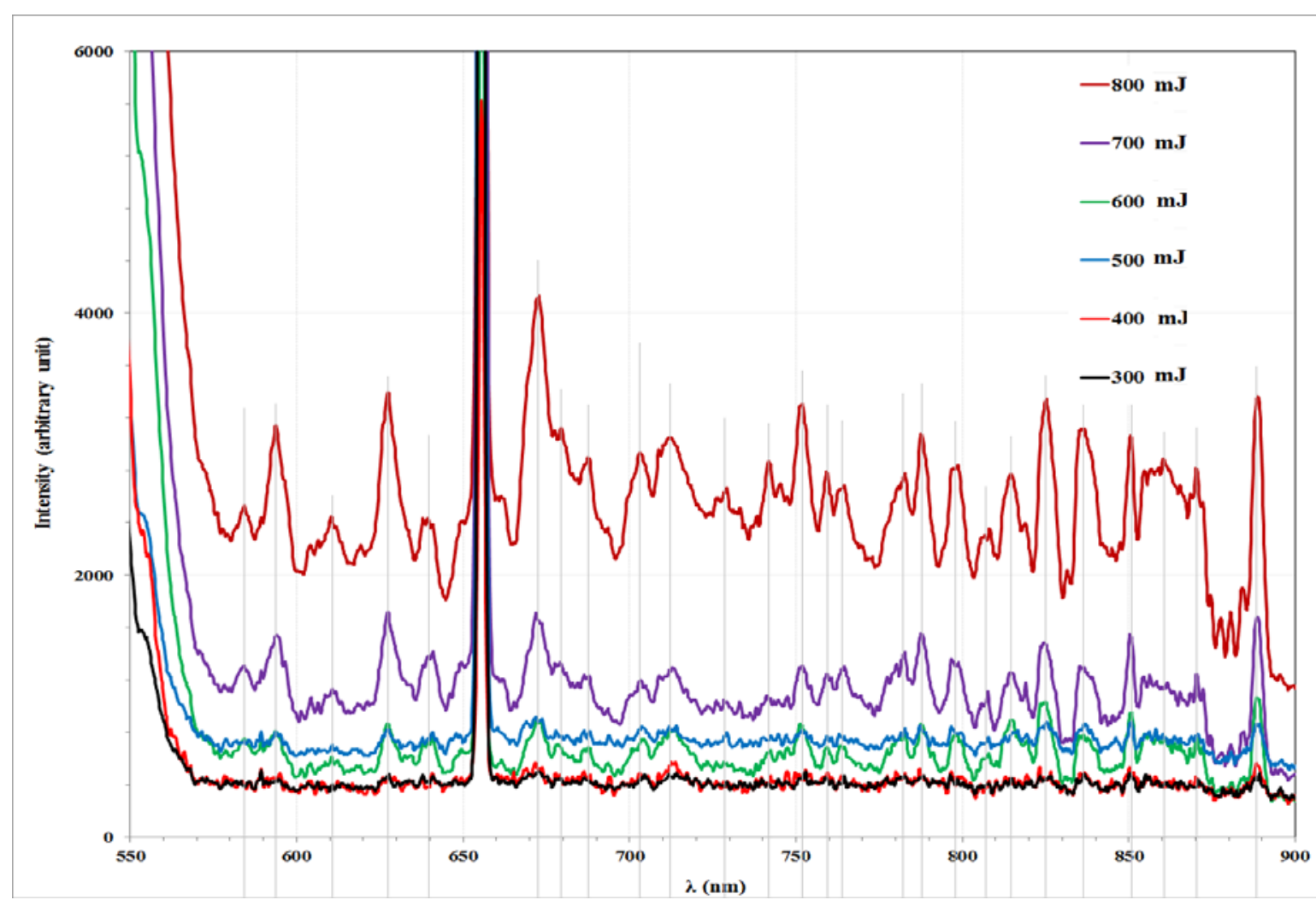

Fig. 7: Emission spectra induced by $532 \mathrm{~nm}$ laser, with different laser energies for Ag:Al alloy in distilled water.

\section{Conclusions}

Study the effect laser energies on spectra for plasma glow produced by pulse Nd:YAG laser for different wavelength $(\lambda=532$ and $1064 \mathrm{~nm})$ on Ag:Al alloy show many points as follows:

- Using $1064 \mathrm{~nm}$ laser, the electron temperature increase exponentially from 1.698 to $1.899 \mathrm{eV}$, while the electron density decrease from $2.247 \times 10^{15}$ to $5.08 \times 10^{14} \mathrm{~cm}^{-3}$ with increasing laser energy from 300 to $800 \mathrm{~mJ}$.

- Electron temperature using $532 \mathrm{~nm}$ are greater than with $1064 \mathrm{~nm}$, and increase exponentially from 2.405 to $2.444 \mathrm{eV}$, while the electron density decrease from $2.210 \times 10^{15}$ to $1.516 \times 10^{15}$ with increasing laser energy from 300 to $800 \mathrm{~mJ}$.

- All plasma parameters satisfy plasma conditions.

- New peaks appeared in the range of 580 to 890 when we use $532 \mathrm{~nm}$ laser corresponding to one of emission band for water molecules.

\section{References}

[1] D. M. Devia, L. V RodriguezRestrepo, E. Restrepo-Parra, Ing. y Cienc., 11, 21 (2015) 239-267.

[2] V. Thongpool, P. Asanithi, P. Limsuwan, Procedia Eng., 32 (2012) 1054-1060.

[3] C. Aragou and J. Aguilera, Spectrochim. Acta Part B, vol. 63 (2008) 893-916.

[4] N. Shaikh, A. Nizamini, A. Moghal, Sindh Univ. Res. J.Science Ser, 45, 2 (2013) 399-403.

[5] M. Zhukov, Plasma Diagnostics, Cambridge International Science Publishing, Ch. 5, UK, 2005.

[6] S. S. Hamed, Egypt J. Solids, 28, 2 (2005) 349-357.

[7] M. G. Umran Inan, Principles of Plasma Physics for Engineers and Scientists, Ch. 4, New York, 2011.

[8] S. Eliezer, The Interaction of HighPower Lasers With Plasmas, 45, 2 
(2003) 181-181.

[9] J. E. Sansonetti and W. C. Martin, Am. Inst. Phys., 34, 4 (2005) 20092012.

[10] J. Huang, C. Ke, L. Huang, K. L. U, Spectrochim. Acta Part B, 57 (2002) 35-48.

[11] Z. Wang, L. Li, L. West, Z. Li, W. $\mathrm{Ni}$, Spectrochim. Acta Part B At. pectrosc., 68 (2012) 58-64.
[12]M. Musadiq, N. Amin, Y. Jamil, M. Iqbal, M. A. Naeem, H. Akif, Int. J. Eng. Technol., 2, 1 (2013) 32-43.

[13] Y.F. Lu and M.H. Hong, Appl. Phys. 86 (1999) 2812-2819.

[14] R. Schermaul, R. C. M. Learner, D. A. Newnham, R. G. Williams, J. Ballard, N. F. Zobov, D. Belmiloud, and J. Tennyson, J. Mol. Spectrosc., 208 (2001) 32-42. 